\title{
Plastics in the shadow of the coronavirus: Don't prohibit, teach instead!
}

\author{
T. Czigany ${ }^{1,2^{*}}$, F. Ronkay ${ }^{1,3}$ \\ ${ }^{1}$ Department of Polymer Engineering, Faculty of Mechanical Engineering, Budapest University of Technology and \\ Economics, H-1111 Budapest, Müegyetem rkp. 3, Hungary \\ ${ }^{2}$ MTA-BME Research Group for Composite Science and Technology, H-1111 Budapest, Müegyetem rkp. 3., Hungary \\ ${ }^{3}$ Imsys Ltd, Material Testing Laboratory, Mozaik Street 14/A., H-1033 Budapest, Hungary
}

This paper was published on $31^{\text {st }}$ March 2021

Our article, 'The coronavirus and plastics' (https:// doi.org/10.3144/expresspolymlett.2020.41) was published exactly one year ago, in which we highlighted the importance of plastics in connection with the coronavirus pandemic.

In the article, we emphasized the importance of masks covering the mouth and nose because, at that time, many people considered them unnecessary (among them, unfortunately, many politicians who influenced the opinion of the people). Perhaps, our article contributed a little to the widespread wearing of masks worldwide, which is an essential tool for slowing down the pandemic. At that time, we could not foresee that the number of people infected with Covid-19 would increase more than 150-fold (from 850583 to 128224509 ) in a single year (between 31 March 2020 and 31 March 2021) and the number of deaths nearly 68-fold (from 41494 to 2803806 source: Johns Hopkins University, Center for Systems Science and Engineering). This also shows what an aggressive virus the world has to face. The governments immediately ordered curfews and locked down cities and whole countries. The catastrophic consequences of lockdowns are apparent, not only in the economy but also in society due to narrowed human relationships and the closing of schools. Many studies address the sociological, health, moral and other aspects of lockdowns. It is not surprising that, in the second and third wave, governments waited longer before locking down the economy and schools. Our field, training engineers and R\&D, are especially practice-intensive. Practical skills cannot be taught, laboratory tests cannot be performed over the Internet. The students must be present and have to experience it.

We have had several direct reactions to our earlier article which can be divided into two groups: some consider the problem of plastic waste comparable to the social and economic catastrophe associated with the virus (e.g., https://doi.org/10.1007/s10311-02001129-z). Others agreed with us that plastics offer indispensable tools to fight the pandemic, and the generated waste can be handled safely - it is only a question of motivation and will - 'where there is a will, there is a way' (e.g., https://doi.org/10.3389/ fmats.2020.00283).

The past year of the coronavirus has shown (what plastic experts have always known) that there is no life without plastics, and plastics are essential in handling the pandemic. Think about it: most medical tools are made of plastic (e.g. ventilator tubes). Plastic protection devices have become the most sought after products in the world: coats, gloves, masks and face shields. Demand for transparent plastics has increased, especially for PMMA, PETG and PC, not only because of face shields, but also because of 
barriers to separate people (for example, workers on assembly lines are separated with them, and so are desks in offices and cashiers from customers in shops).

Another remarkable effect of the pandemic is that there are fewer attacks on plastic packaging in the media. This is especially interesting because food delivery and food takeaway have increased significantly, and there is also considerable growth in the use of plastic boxes and foamed trays that retain heat. As a result of increased consumption of vitamins, the use of blister packs and plastic bottles has also increased significantly.

Many people have realized, perhaps for the first time, that injection moulded or vacuum-formed packaging does have not only an aesthetic role but also an important functional and hygienic role. When discarding the packaging, you also get rid of possible virus contamination on it.

A very positive community experience was 3D printing in homes based on designs shared on the Internet, with which many protective devices were produced for individuals and local hospitals.

A great success of virologists and doctors is that there are vaccines available and more and more people are vaccinated. At the same time, humankind faces a challenge - the fast and organized administering of vaccines. The fight between countries to acquire more vaccines on the world market increases; whether politicians or governing parties remain in power depends on the fast and organized acquisition of vaccines and vaccination. All these can lead to 'vaccine war'.

While the mask has been the most commonly used plastic product since the beginning of the pandemic, in the period of vaccination, it is the plastic syringe. According to some experts, $70 \%$ of people in the world have to be vaccinated to get rid of the virus, which means 5.5 billion people. Since most of the currently available vaccines require two shots (hoping that they will provide long-term protection), this means 11 billion vaccines and the same number of plastic syringes. One syringe is about 3 grams. Multiply it by 11 billion, and it is theoretically 33 million kilograms or 33 thousand tons of typically PE or PP plastic of excellent properties.

The plastics are needed, that is without question. However, politicians often choose the easier way and do not consider the ecological footprint of materials; and if people throw them away, they ban them instead of changing the incorrect behaviour by promoting recycling and reuse. We strongly think this is not the right approach - plastics should not be banned since it is not the fault of the materials if people throw them away indiscriminately and irresponsibly. Instead, people should be taught in early childhood that waste should be collected selectively, be it paper, metal or plastic (https://doi.org/10.3144/expresspolymlett. 2020.1). It is essential that plastics are used responsibly where it is necessary for sustainable development and, especially now, in fighting the coronavirus pandemic. However, we have to be careful - more and more masks are thrown away in public places, and they have also appeared in rivers and seas. (https://doi.org/10.1016/j.wasman.2020.09.029). Fortunately, the handling of syringes used by medical personnel is governed by strict rules, which effectively prevents them being thrown away and polluting the environment. This way, there is no risk that politicians may ban them, following the train of thought above.

Important: Don't prohibit but think and teach so that we can live in a more sustainable world! Homo Sapiens instead of Home Office! 